Research Articles

\title{
Levels of Aflatoxin M1 in Different Types of Milk Collected in Jahrom, Iran, Winter-Spring 2013
}

\author{
${ }^{1}$ Reyhaneh Rouhi, ${ }^{2}$ Akbar Kazemi, ${ }^{2}$ Abdolreza Sotoodeh Jahromi, \\ ${ }^{2}$ Hasdsan Zabetian, ${ }^{2}$ Hossien Hakimelahi, ${ }^{2}$ Alireza Yusefi and ${ }^{3}$ Abdolhossien Madani \\ ${ }^{1}$ Research Center for Social Determinants of Health, \\ Jahrom University of Medical Sciences, Jahrom, Iran \\ ${ }^{2}$ Zonoses Research Center, Jahrom University of Medical Sciences, Jahrom, Iran \\ ${ }^{3}$ Research Center for Social Determinants in Health Promotion, \\ Hormozgan University of Medical Sciences, Bandarabbas, Iran
}

Article history

Received: $20-12-2014$

Revised: 29-12-2014

Accepted: 18-8-2015

Corresponding Auhtor: Abdolreza Sotoodeh Jahromi Zonoses Research Center, Jahrom University of Medical Sciences, Jahrom, Iran Email: sotoodehj2002@yahoo.com

\begin{abstract}
Aflatoxins as a group of mycotoxins, are produced by Aspergillus species under environments that favor the growth of molds. Aflatoxin M1 (AFM1) has been considered as a class 2Bcarcinogen. As milk is a major nutrient, extensive attention must be taken on the presence of AFM1 in commercial milk and dairy foods. The aim of this study was to evaluate AFM1 contamination in raw and pasteurized milk consumed in Jahrom city located in southern of Iran. The level of AFM1 in 120 milk samples collected from winter to spring 2013 from Jahrom, Iran market or domestically produced was determined using ELISA method. There was significant difference between the mean concentration AFM1 in milk collected during winter $(7.53 \pm 12.86 \mathrm{ng} / \mathrm{L})$ and spring $(21.56 \pm 28.84 \mathrm{ng} / \mathrm{L})$, $\mathrm{p} \leq 0.001$. Inspection of milk and dairy products is recommended for AFM1 contamination speciallly during winter.
\end{abstract}

Keywords: Aflatoxin M1, Pasteurized Milk, Raw Milk, Iran

\section{Introduction}

Aflatoxins as a group of mycotoxins, are produced by Aspergillusspecies under environments that favor the growth of molds (Van Egmond, 1991).

Animals are exposed to mycotoxins such as the aflatoxins (AFs) by consumption of feeds contaminated by mycotoxin-producing molds during growth, harvest and/or storage. When lactating cows consume aflatoxin B1 (AFB1) contaminated feed, AFB1 ismetabolized to form the monohydroxy derivative, aflatoxin M (AFM1), which is produced in the cow's milk. The AFM1 is the mainhydroxylated derivative of AFB1 formed in liver by means of P450cytochrome enzymes and secreted into milk through the mammary gland of dairy cows (Van Egmond, 1991) and defecated as AFM1 in urine and also in milk (Vagef and Mahmoudi, 2013). AFM1 has been considered by the International Agency for Research on Cancer as a class 2 Bcarcinogen and its carcinogenicity was valued to be one-tenth of that of AFB 1 by the Joint Expert Committee on Contamination and Food Additives in 2001 (FAO/WHO, 1999).
As milk is considered to be a perfect natural food for consumers of all age groups due to its high nutritional value, extensive attention must be taken on the presence of AFM1 in commercial milk and dairy foods (Oveisi et al., 2007). The European Commission Regulation 1881/2006 sets a maximum limit of $0.05 \mathrm{mg} / \mathrm{kg}$ for AFM1 in raw milk, heat-treated milk and milk for the manufacture of milk based products (CAC, 2001).

AFM1 is moderately stable during pasteurization, sterilization, preparation and storing of different dairy products (Fallah, 2010).

Infants in Iran usually consume pasteurized and sterilized milk after breast stopping and up to 3 years of age as the basic source of food, so the problem is most important in this age group (Oveisi et al., 2007).

Therefore, it is vital to evaluate AFM1 level in milk and dairy foods in order to inform customers about its potential hazard. There is little information on the basic diet, including milk and milk products as well as AFM1 concentrations in milk, in some cities of Iran (Tajkarimi et al., 2007).

The aim of this survey was to determine AFM1 concentrations in raw and pasteurized milk marketed 
in Jahrom city located in southern of Iran during winter and spring 2013.

\section{Materials and Methods}

A total 120 milk samples were randomly collected from supermarkets in Jahrom (a southern city in Iran), during winter and spring 2013. Of these, 90s samples were raw milk and 30 samples were pasteurized milk. All of the samples were transported at $2-4^{\circ} \mathrm{C}$ in the cold box to the laboratory and centrifuged at $3500 \mathrm{~g}$ for 10 $\min$ at $10^{\circ} \mathrm{C}$. The upper creamy layer was removed by Pasteur pipette and lower liquid was evaluated for AFM1 concentration. The quantitative analysis of AFM1 in samples was performed by competitive ELISA using commercial AFM1 test kit (R-Bio pharm AG, Darmstadt, Germany).
According to Iranian national standard and accentuated by European Union (EU) and codex Alimentarious Commission, (European Commission (EC), the presence of AFM1 level more than $50 \mathrm{ng} / \mathrm{l}$ in milk, considered as positive and less than $50 \mathrm{ng} / \mathrm{l}$ considered as negative for AFM1 (CAC, 2001).

The results analysis was done by one-way Analysis Of Variance (ANOVA) and considered statistically difference at $95 \%$ confidence levels.

\section{Results}

The result of analyses of AFM1level showed that 10 milk samples $(8.33 \%)$ including 6raw milk samples $(6.7 \%)$ of and 4 pasteurized milk samples $(13.3 \%)$ of had positive AFM1 contamination, i.e., higher than standard limitation (50 ng/l).

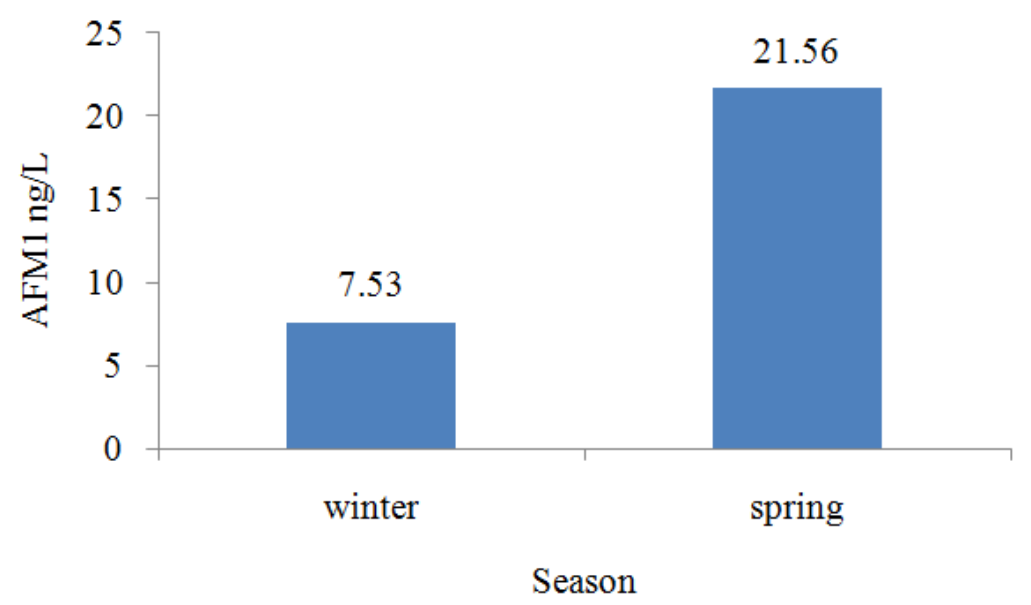

Fig. 1. AFM1 mean contamination in milk samples collected in different seasons

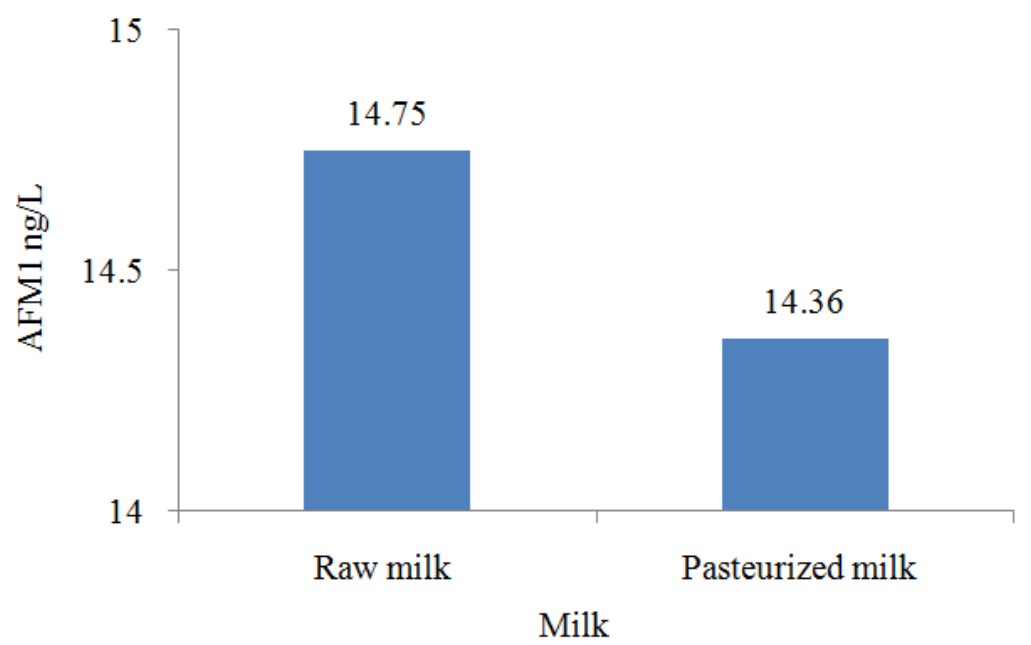

Fig. 2. AFM1 mean contamination percentage in milk samples 
There was not found significant difference between the level of AFM1 in raw and pasteurized milk samples $(\mathrm{p}>0.05)$.

There was significant difference between the mean concentration AFM1 in milk collected during winter $(7.53 \pm 12.86 \mathrm{ng} / \mathrm{L})$ and spring $(21.56 \pm 28.84 \mathrm{ng} / \mathrm{L})$, ( $\mathrm{p} \leq 0.001$ ), (Fig. 1).

There was not significant difference between the mean concentration AFM1 in raw milk $(14.75 \pm 21.76 \mathrm{ng} / \mathrm{L})$ and pasteurized milk (14.36 $\pm 28.31 \mathrm{ng} / \mathrm{L}),(\mathrm{p}=0.164)$, (Fig. 2).

\section{Discussion}

The results of this study showed that $8.33 \%$ consuming milk in Jahrom as a city in southern of Iran had AFM1contamination more than $50 \mathrm{ng} / \mathrm{l}$.

In present study the level of AFM1 in raw and pasteurized milk samples showed no significant difference $(\mathrm{P}=0.164)$.

There are few literature data on the occurrence of AFM1levels in milk and milk products in Iran (Oveisi et al., 2007; Tajkarimi et al., 2007; Tajik et al., 2007; Kamkar, 2005; Alborzi et al., 2006).

The AFM1 mean contamination found in present study is lower than reported in other cities of Iran (44-76 ng/l) (Tajkarimi et al., 2007; Tajik et al., 2007; Kamkar, 2005; Alborzi et al., 2006).

Our results about the prevalence positive AFM1contamination of pasteurized milk and raw milk are in agreement with Shiraz (southern city of Iran) $17.8 \%$ (Alborzi et al., 2006) and with the result of study in Urmia (north-west city of Iran) 6.25\% (Tajik et al., 2007).

AFM1levels in milk produced in Argentina were found to be very low and in no case did the levels exceed the recommended limits for milk products $(50$ $\mathrm{ng} / \mathrm{L})$ (Lopez et al., 2003). The incidence of positive AFM1 milk contamination rate were reported $80.6 \%$ and 64\% in Portugal (Martin and Martin, 2000) and Turkey (Çelik et al., 2005), respectively.

AFM1 contamination of milk is the result of cows feeding byAFB1 having material. The concentration of this mycotoxin in animal feedstuffs is influenced by the type, the time and system of harvesting and temperature and relative dampness of storage facilities, all of each factors are changed in various cities of Iran (Tajkarimi et al., 2007).

In present study, there was significant difference between the mean concentration AFM1 in milk collected during winter and spring, $(\mathrm{p} \leq 0.001)$ which is in agreement with the results of other researches. For instance, Tajkarimi reported that AFM1 level in milk samples were significantly higher in winter than in summer (Tajkarimi et al., 2008).

Milk AFM1 contamination found in our study are similar to those reported in other countries, especially those in Asian and Africa, although higher than those in many European countries (Wood and Trucksess, 1998).
To reduce the level of AFM1, it is essential to conduct training programs for producers about the toxicity potential of aflatoxins, decrease AFB1concentration in animal feed by approperiate manufacturing and storage, integrating it with Hazard Analysis and Critical Control Points (HACCP) based safety program and performance regular monitoring and evaluation of milk and milk products for AFM1 level (Dairy HACCP-Evaluation, 2003).

\section{Conclusion}

The results indicated that the milk AFM1 contamination in such level could be a hazardous for public health. For this reason, milk and dairy products should be inspected and controlled unceasingly for AFM1 contamination. Where concentrations are unacceptably high, careful investigation of feedstuffs for AFB1 contamination are suggested.

\section{Acknowledgment}

The authors wish to thank the vice chancellor for research of Jahrom University of Medical Sciences for supporting this study.

\section{Funding Information}

This work was financed by Jahrom University of Medical Sciences.

\section{Authors' Contributions}

All authors had read and approved the final manuscript:

Reyhaneh Rouhi and Akbar Kazemi: Participated in Designed the study, data collection and contributed to the revision of the manuscript.

Abdolreza Sotoodeh Jahromi, Hasdsan Zabetian, Alireza Yusefi, Hossien Hakimelahi and Abdolhossien Madani: Carried out data collection, analysis and writing the manuscript.

\section{Ethics}

All dairy companies whose milk were evaluated in this research, will be kept anonumus.

\section{Competing Interests}

The authors declare that they have no competing interests.

\section{References}

Alborzi, S., B. Pourabbas, M. Rashidi and B. Astaneh, 2006. Aflatoxin M1 contamination in pasteurized milk in Shiraz (South of Iran). Food Control, 17: 582-584. DOI: 10.1016/j.foodcont.2005.03.009 
CAC, 2001. Comments submitted on the draft maximum level for aflatoxin $\mathrm{M}_{1}$ in milk. In Codex committee on food additives and contaminants 33rdsession. Hauge, Codex Alimentarius Commission, Netherlands.

Çelik, T.H. and B. Sarımehmetoğlu and Ö. Küplülü, 2005. Aflatoxin M1 contamination in pasteurised milk. Veterinarski Arhiv, 75: 57-65.

Dairy HACCP-Evaluation, 2003. NCIMS HACCP pilot program phase II expansion. National Conference on Interstate Milk Shipments (NCIMS) Table of Contents, Return to Dairy Grade A Voluntary HACCP.

Fallah, A.A., 2010. Aflatoxin M1 contamination European Commission Regulation, No 466/2001/EC of 8 March 2001, setting maximum levels for certain contaminants in food stuffs. Official J. Eur. Commission Lo, 77: 1-13.

FAO/WHO, 1999. Forty ninth report of the joint FAO/WHO expert committee of food additives: Evaluation of certain food additive and contaminations. WHO Technical Report Series.

Kamkar, A., 2005. A study on the occurrence of aflatoxin M1 in raw milk produced in Sarab city of Iran. Food Control, 16: 593-599. DOI: 10.1016/j.foodcont.2004.06.021

Lopez, C.E., L.L. Ramos, S.S. Ramadan and L.C. Bulacio, 2003. Presence of aflatoxin M1 in milk for human consumption in Argentina. Food Control, 14: 31-34. DOI: 10.1016/S0956-7135(02)00049-X

Martin, M.L. and H.M. Martin, 2000. Aflatoxin M1 in raw and ultra high temperature-treated milk commercialized in Portugal. Food Additives Contaminants, 17: 871-874.

DOI: $10.1080 / 026520300420457$
Oveisi, M.R., B. Jannat, N. Sadeghi, M. Hajimahmoodi and A. Nikzad, 2007. Presence of aflatoxin $M_{1}$ in milk and infant milk products inTehran, Iran. Food Control, 18: 1216-1218.

DOI: $10.1016 /$ j.foodcont.2006.07.021

Tajik, H.S., M.R. Rohani and M. Moradi, 2007. Detection of Anatoxin Ml in Raw and Commercial Pasteurized Milk in Urmia, Iran. Pak. J. Biological Sci., 10: 4103-4107

Tajkarimi, M., F. Aliabadi-Sh, A.S. Nejada, H. Poursoltania and A.A. Motallebic et al., 2008. Aflatoxin M1 contamination in winter and summer milk in 14 states in Iran. Food Control, 19: 1033-1036. DOI: 10.1016/j.foodcont.2007.10.011

Tajkarimi, M., F.S. Aliabadi, M.S. Nejad, H. Pursoltani and A.A. Motallebi et al., 2007. Seasonal study of aflatoxin $\mathrm{M}_{1}$ contamination in milk in five regions in Iran. Int. J. Food Microbiol., 116: 346-349. DOI: 10.1016/j.ijfoodmicro.2007.02.008

Vagef, R. and R. Mahmoudi, 2013. Occurrence of Aflatoxin M1 in raw and pasteurized milk produced in west region of Iran (during summer and winter). Int. Food Res. J., 20: 1421-1425.

Van Egmond, H.P., 1991. Mycotoxins. Bull. Int. Dairy Federation, 9: 131-145.

Wood, G.E. and M.W. Trucksess, 1998. Regulatory Control Programs for Mycotoxin-Contaminated Food. In: Mycotoxins in Agriculture and Food Safety, Shinha, K.K. and D. Bhatnagar (Eds.), CRC Press, ISBN-10: 0824701925, pp: 459-451. 